\title{
Aspectos biomecânicos compressivos de diáfises femorais caninas conservadas em glicerina a $98 \%$ ou em mel
}

\author{
Biomechanical compressive aspects of canine femoral shafts preserved in $\mathbf{9 8 \%}$ glycerin or honey
}

\author{
Gustavo Frassetto Amendola' Alceu Gaspar Raiser ${ }^{\mathrm{II}}$ José Mario Doley Soares $^{\mathrm{III}}$ \\ Diego Vilibaldo Beckmann ${ }^{\mathrm{I}}$
}

\section{RESUMO}

Neste estudo foi comparada a resistência compressiva axial de diáfises femorais caninas a fresco (grupo F), conservadas por trinta dias em glicerina a 98\% (grupo G) ou em mel (grupo M). Cada grupo continha 50 amostras que foram submetidas a testes biomecânicos compressivos, em uma prensa de compressão axial, até ocorrer fissura. Os ossos conservados em glicerina ou mel foram reidratados antes da avaliação. Pelos resultados obtidos, foi verificada maior resistência nos ossos conservados em glicerina, depois nos ossos conservados em mel, sendo mais frágeis aqueles testados a fresco.

Palavras-chave: enxerto ósseo, resistência, glicerina, mel.

\section{ABSTRACT}

This study aimed at evaluating the axial compressive resistance of fresh canine femoral shafts (group F), canine femoral shafts preserved in $98 \%$ glycerin (group G) or honey (group M) for a 30-day period. The femoral shafts (50 samples in each group) were submitted to biomechanical evaluation in a machine of axial compression in order to observe the pressure necessary to determine bone fissure. The shafts preserved in $98 \%$ glycerin or honey were rehydrated in saline $0.9 \%$ before evaluation. Bones stored in $98 \%$ glycerin have more resistance than bones preserved in honey and fresh implants presented the worst performance.

Key words: bone graft, resistance, glycerin, honey.

\section{INTRODUÇÃO}

Os aloenxertos ósseos corticais são biodegradáveis e, comumente, usados no tratamento de fraturas em mamíferos. GOLDBERG \& STEVENSON (1987) utilizaram ossos coletados a fresco, entretanto os enxertos podem ser conservados para posterior implantação. Os vários meios e métodos de conservação de ossos corticais visam a diminuir a antigenicidade das células do doador a serem implantadas no hospedeiro, além de manterem um estoque acessível quando necessário(STEVENSON, 1998).

Quanto a métodos de conservação de implantes ósseos, várias são as alternativas para conservar o osso cortical alógeno de cães, como a liofilização (COSTA, 1996), o tiomersal (DEL CARLO, 1999), o óxido de etileno (CASTANIA, 2002), a glicerina (ZILIOTTO et al., 2003) e o mel (ALIEVI, 2006).

Diversos autores como KOMANDER (1976), BURCHARDT et al. (1978), PELKER et al. (1984) e SALBEGO et al. (2006) realizaram testes de resistência óssea. Basicamente os ensaios podem ser destrutivos e não-destrutivos. O primeiro promove a ruptura ou a inutilização do material e, nessa categoria, estão incluídos os testes de tração, impacto, torção, compressão, flexão e fadiga. Os ensaios não-destrutivos incluem os testes de ultra-som, magnoflux, raios-X e outros que podem determinar as propriedades físicas ou mecânicas do material analisado (SOUZA, 1974).

O tipo de ensaio biomecânico empregado depende do tipo de material a ser testado, da finalidade a que se destina, dos tipos de esforços aos quais será

\footnotetext{
'Programa de Pós-graduação em Medicina Veterinária (PPGMV), Universidade Federal de Santa Maria (UFSM), Santa Maria, RS, Brasil.

"Departamento de Clínica de Pequenos Animais, Centro de Ciências Rurais (CCR), UFSM, 97105-900, Santa Maria, RS, Brasil. Email: raisermv@smail.ufsm.br. Autor para correspondência.

IIIDepartamento de Transportes, UFSM, Santa Maria, RS, Brasil.
} 
submetido e das propriedades mecânicas a serem medidas. Para a análise de enxertos ósseos, um dos testes mais importantes a ser realizado é o de compressão axial (CASTANIA, 2002).

A glicerina tem sido empregada com sucesso na conservação de ossos conforme se verifica nas publicações de COSTA (1996), MELO et al. (1998) e ZILIOTTO et al. (2003) ao efetuarem reparação de falhas ósseas segmentares nos membros de cães. DEL CARLO et al. (1999) aplicaram aloimplantes ósseos em cães e verificaram que, de seis métodos de conservações estudados, a glicerina a $98 \%$ e o congelamento foram os métodos que proporcionaram melhor resultado clínico, porém a glicerina tornou o osso quebradiço exigindo longo período de hidratação. COSTA (1996) citou que a liofilização e a glicerina são bons métodos de conservação de ossos, no entanto, ambos afetam as suas propriedades biomecânicas.

Embora o mel seja pouco utilizado como conservante de implantes ósseos, com base na evidência de que ele possui propriedades conservantes (EFEM et al., 1992), os ossos nele conservados por um período de 30 dias, quando implantados em animais, proporcionaram resultados satisfatórios (ALIEVI, 2006). LUCAS et al. (2001) submeteram a ensaio compressivo axial, destrutivo, ossos inteiros conservados em glicerina, mel ou congelamento, sem reidratação, e constataram que os conservados em mel foram mais resistentes.

Este estudo buscou comparar biomecanicamente, por meio de compressão axial, a resistência óssea de diáfises femorais conservadas em glicerina ou mel e aquelas obtidas a fresco.

\section{MATERIAL E MÉTODO}

Foram coletadas diáfises femorais provenientes de cães que vieram a óbito e foram encaminhados ao Setor de Patologia do Hospital Veterinário Universitário da Universidade Federal de Santa Maria (UFSM). A coleta foi realizada apenas em cães hígidos, sem histórico clínico de enfermidades sistêmicas ou infectocontagiosas ou deformidades ósseas que pudessem interferir nos resultados.

Os fêmures direito e esquerdo de cada canino tiveram suas diáfises coletadas de forma não-asséptica. As suas extremidades foram removidas mediante secção transversal com auxílio de serra manual de modo a resultar em um segmento diafisário cujo comprimento foi duas vezes o seu diâmetro externo. A seguir, foram removidos a medula óssea e o periósteo e cada amostra foi acondicionada em glicerina a $98 \%$ ou mel, respectiva e alternadamente. $\mathrm{O}$ intervalo entre a coleta e a realização dos ensaios biomecânicos foi de 30 dias.

Foram formados grupos denominados $G_{1-50}$ (glicerina) e $\mathrm{M}_{1-50}$ (mel), ou seja, 50 ossos (numerados de 1 a 50) conservados em glicerina (25 do membro direito e 25 do esquerdo) e outros 50 (25 do membro direito e 25 do esquerdo) conservados em mel. Em ambos os grupos sempre foram comparados os ossos do mesmo doador, ou seja, a diáfise do membro direito de determinado cão foi conservada em glicerina e o esquerdo em mel. Um terceiro grupo (controle) foi formado por ossos colhidos a fresco $\left(\mathrm{F}_{1-50}\right)$, composto por 50 corpos de prova que foram testados logo após a coleta.

Os testes de resistência foram realizados no Laboratório de Materiais de Construção Civil da UFSM com auxílio de uma prensa de compressão axial (Figura 1). Esta exerceu uma força sobre os ossos, revelando um valor de leitura (L), o qual, posteriormente, foi convertido para a unidade Newton $(\mathrm{N})$ pela fórmula $\mathrm{P}=15,322 \times \mathrm{L}+$ 4,45 em que P é o resultado final em N. A compressão exercida pela prensa foi feita manualmente, acionando lenta e progressivamente um sistema de cremalheiras. Foi padronizado que, no momento em que surgisse o primeiro sinal de fissura ou de solução de continuidade em conseqüência da compressão, essa seria interrompida e o valor obtido seria aferido. A referida prensa possui um anel de deformação que foi comprimido contra o osso a ser testado, o qual foi interposto entre as plataformas de compressão. Quanto maior fosse a alteração no perímetro do anel, maior seria o valor da leitura (L).

Os ossos foram medidos com paquímetro digital determinando-se a espessura média da camada cortical. A seguir foi mensurado o sentido craniocaudal e mediolateral de cada diáfise obtendo-se uma média do seu diâmetro, padronizando-se o seu comprimento para ser o dobro do diâmetro. Com esses dados foi possível calcular o volume de cada osso por meio da fórmula do cilindro oco: $\mathrm{V}=\pi \times \mathrm{h} \times\left(\mathrm{R}^{2}-\mathrm{r}^{2}\right)$, em que:

$\mathrm{V}=$ volume em cm $\mathrm{cm}^{3} ; \pi=3,14159 ; \mathrm{h}=$ altura (comprimento do osso); $\mathrm{R}$ = raio maior (metade do diâmetro externo); $\mathrm{r}$ = raio menor (metade do diâmetro interno). Os dados obtidos foram avaliados por meio do teste t pareado e por correlação linear entre volume $\left(\mathrm{cm}^{3}\right)$ e carga $(\mathrm{N})$. O programa utilizado para avaliar estatisticamente os dados foi o PRISM 4.0 for Windows GraphPad, Califórnia.

As extremidades superior e inferior do cilindro ósseo (diáfises) foram alinhadas de modo que o ângulo reto formado entre o eixo maior e a base fosse consistente com o mesmo e a porção superior. Antes da realização dos ensaios foi promovida a hidratação dos ossos conservados na glicerina ou no mel, em 


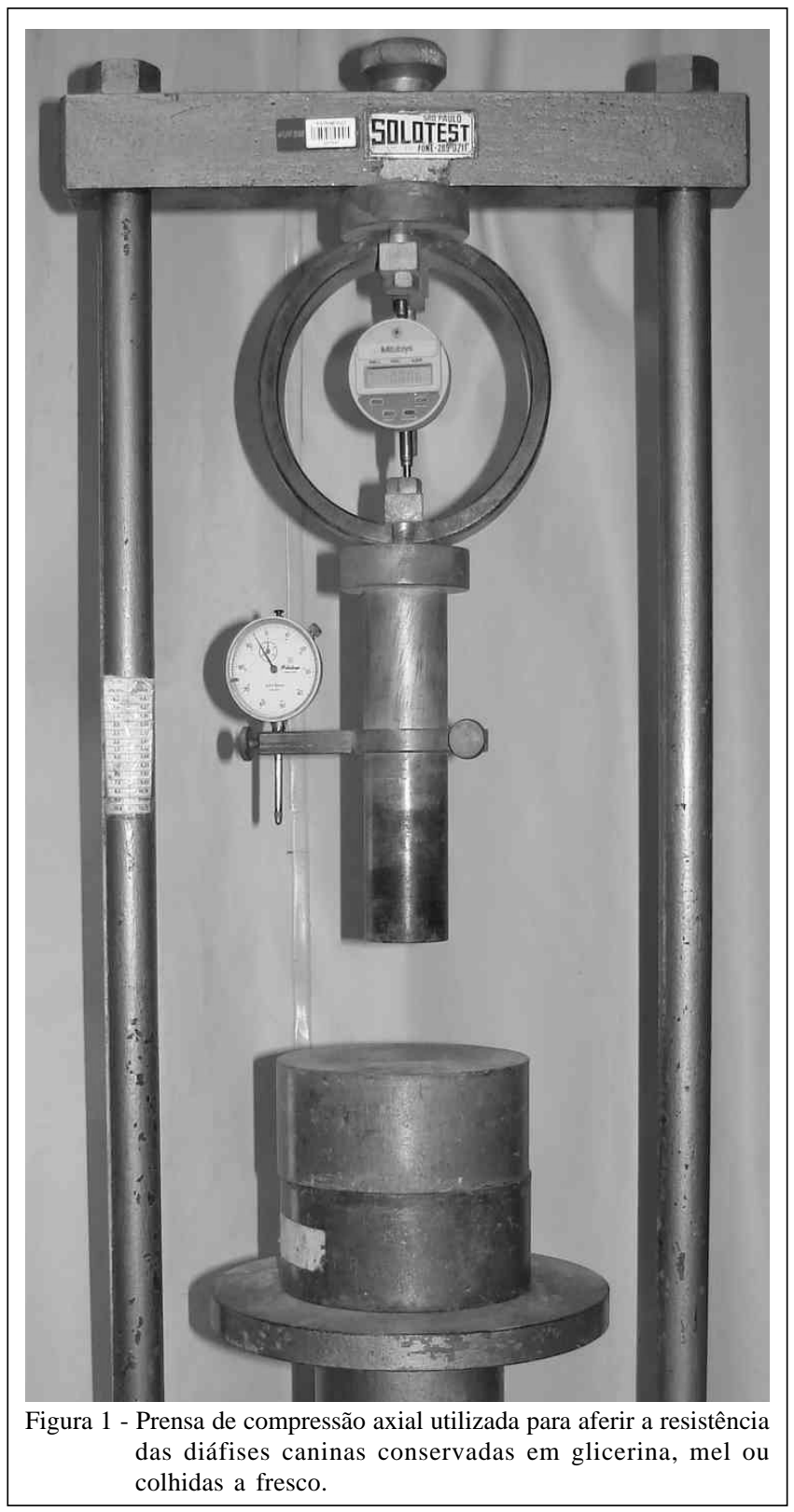

solução fisiológica $0,9 \%$, em temperatura ambiente, por um período de seis horas. Os ossos testados a fresco não foram submetidos a esse processo por não estarem desidratados.

\section{RESULTADOS E DISCUSSÃO}

Nos três grupos avaliados, verificou-se que as diáfises que suportaram maior força compressiva foram aquelas conservadas em glicerina (Média de $6339,939 \mathrm{Ncm}^{-3}$ ), depois as conservados em mel $\left(5906,387 \mathrm{Ncm}^{-3}\right)$ e, por fim, aquelas colhidas a fresco $\left(4888,532 \mathrm{Ncm}^{-3}\right)$.
Os ossos coletados a fresco foram testados não apenas como controle, mas também porque, segundo GOLDBERG \& STEVENSON (1987), proporcionam melhores resultados biomecânicos. Entretanto, eles têm se mostrado insatisfatórios devido à resposta imunogênica e à lenta incorporação. Assim, os métodos de conservação buscam não só a disponibilidade nos bancos, mas também a diminuição da antigenicidade. Meios de conservação como a glicerina e o mel alcançam esse objetivo, porém desidratam o osso, diminuindo a sua resistência tênsil.

Os resultados obtidos na presente pesquisa precisam ser analisados com certo cuidado. As diáfises conservadas em glicerina efetivamente mostraram-se mais resistentes que aquelas conservadas em mel, pois cada uma daquelas testadas na glicerina foi comparada com a sua contralateral que fora conservada no mel. O mesmo não ocorreu com as diáfises testadas a fresco (grupo controle), pois como cada cão possui apenas dois ossos femorais, o controle foi sempre de outro animal. Durante os testes, embora matematicamente alguns ossos a fresco fossem maiores e suportassem maior carga em valores totais, proporcionalmente suportaram menor carga compressiva por $\mathrm{cm}^{3}$. Para BRIANZA et al. (2006), se for avaliada a resistência de uma amostra óssea de volume padronizado, de animais de mesmas dimensões e pesos, mas de raças diferentes, ainda assim os valores seriam diferentes. Isso se deve à geometria óssea distinta, pois, por exemplo, uma secção transversal mais cilíndrica ou mais ovalada e um canal medular mais estreito ou mais amplo influem de forma significativa na resistência.

No teste t pareado foi estipulado que as diáfises conservadas em glicerina possuíam as mesmas dimensões volumétricas daquelas conservadas no mel, por serem ossos contra laterais do mesmo animal. Dessa forma, foi possível comparar de forma confiável as médias de carga $(\mathrm{N})$ que cada grupo suportou: 7027,7 $\mathrm{N} \pm 2630,7$ para a glicerina e $6547,0 \mathrm{~N} \pm 2256,7$ para o mel, que foram estatisticamente significativas $(\mathrm{P}=0,0155)$.

A reidratação do osso antes da implantação é um importante fator associado ao seu desempenho estrutural. Pesquisas como a de KOMANDER (1976) demonstraram diminuição da resistência de ossos liofilizados à compressão, enquanto que BURCHARDT et al. (1978) verificaram diminuição e PELKER et al. 
(1984) não observaram alteração significativa nessa propriedade. A glicerina tem se mostrado um eficiente meio de conservação de ossos conforme constataram MELO et al. (1998), no entanto, segundo eles, o meio torna-os quebradiços, exigindo longo tempo de hidratação. LUCAS et al. (2001) verificaram maior resistência naqueles ossos conservados em mel, quando comparados aos conservados em glicerina.

Nas diáfises analisadas no presente experimento mediante reidratação, a maior resistência foi naquelas conservadas em glicerina, quando comparadas àquelas conservadas em mel ou colhidas a fresco. Enquanto ALIEVI (2006) constatou que fêmures caninos conservados em mel não apresentaram fragilidade ao rosqueamento durante a fixação com placas e parafusos, ZILIOTTO et al. (2003) citaram que implantes ósseos conservados em glicerina tornam-se menos resistentes que ossos a fresco, podendo sofrer fraturas no momento da colocação de parafusos. Evidentemente o tipo de estresse aplicado ao osso foi diferente daquele utilizado no atual experimento e a avaliação daqueles autores foi feita de modo subjetivo, ou seja, apenas pela inspeção.

A reidratação de ossos antes da implantação tem sido feita com solução de cloreto de sódio 0,9\% por períodos curtos (ALIEVEI, 2006) ou longos (MELO et al., 1998) com resultados variáveis. Neste experimento, o período teve como referência a pesquisa de SALBEGO et al. (2006), que estudaram a resistência axial de diáfises ósseas após hidratação por uma, seis e 24h, obtendo melhor resultado no grupo de seis horas. $\mathrm{Na}$ atual pesquisa, as diáfises foram reidratadas com solução fisiológica, em temperatura ambiente, sem preocupação com a assepsia, pois, obviamente, não visavam à implantação.

Deve ser levado em conta que o presente estudo foi realizado com ossos obtidos de cadáveres e, portanto, avaliados in vitro sem considerar processos biológicos como a revascularização e a remodelação (PELKER et al., 1984), que atuam no osso in vivo. Por isso, a maioria dos dados provenientes de análises biomecânicas, ao ser extrapolada para a prática clínica, requer um cuidadoso acompanhamento com relatos prospectivos.

Na rotina clínica do Hospital Veterinário Universitário, os implantes têm sido reidratados em solução salina a $0,9 \%$ associada com iodo povidine na proporção de 50:1, por um período de seis horas, em frascos estéreis com tampa para prevenir contaminação e assegurar adequada assepsia, pois tanto o mel como a glicerina não asseguram esterilização. Nos trinta minutos que antecedem a implantação, em sala cirúrgica e com assepsia, o segmento ósseo é lavado e mantido apenas na solução salina para minimizar a presença do iodo. Considera-se que essa metodologia é prática, porque esse tipo de intervenção ortopédica não é emergencial, permitindo a adequada preparação do implante com antecedência.

\section{CONCLUSÃO}

Nas condições sob as quais os ensaios biomecânicos foram realizados na presente pesquisa, pode-se concluir que a glicerina é estatisticamente mais eficiente, em relação o mel, na manutenção da resistência axial e a hidratação é fundamental na retomada da maleabilidade óssea e, dessa forma, na manutenção de sua resistência.

\section{REFERÊNCIAS}

ALIEVI, M.M. Implante ósseo cortical alógeno conservado em mel na reconstituição de falha óssea diafisária em fêmur de cães. 2006. 88f. Tese (Doutorado em Medicina Veterinária) - Universidade Federal de Santa Maria, Santa Maria, RS.

BRIANZA, S.Z.M. et al. Cross-sectional geometrical properties of distal radius and ulna in large, medium and toy breed dogs. Journal of Biomechanics, v.39, n.2, p.302-311, 2006.

BURCHARDT, H. et al. Freee-dried allogenic segmental cortical-bone grafts in dogs. Journal of Bone and Joint Surgery, v.60, n.8, p.1082-1090, 1978.

CASTANIA, V.A. Enxerto córtico-esponjoso homógeno processado quimicamente e esterilizado em óxido de etileno, em cães - análise mecânica e estudo de integração por meio de radiografias. 2002. $72 \mathrm{f}$. Dissertação (Mestrado em Engenharia) - Universidade de São Paulo, São Paulo, SP.

COSTA, J.L. Reconstrução de grande falha óssea com enxerto cortical alógeno conservado em glicerina, fixado com placas e parafusos de aço inoxidável da série 304 estudo experimental em cães. 1996. 100f. Dissertação (Mestrado em Cirurgia) - Universidade Estadual Paulista, Jaboticabal, SP.

DEL CARLO, R.J. et al. Aloenxertos ósseos caninos diferentemente preservados. Revista Brasileira de Ciência Veterinária, v.6, n.3, p.121-126, 1999.

EFEM, S.E.E. et al. The antimicrobial spectrum of honey and its clinical significance. Infection, v.20, n.4, p.227-229, 1992.

GOLDBERG, V; STEVENSON, S. Natural history of autografts and allografts. Clinical Orthopaedics and Related Research, v. 225, p90-91, 1987.

KOMANDER, A. Influence of preservation on some mechanical properties of human haversian bone. Materia Medica Polona, v.8, p.13, 1976.

Ciência Rural, v.38, n.5, ago, 2008. 
LUCAS, S.S. Avaliação biomecânica de três métodos de conservação de ossos para enxerto. In: SEMINÁRIO INTERESTADUAL DE ENSINO, PESQUISA E EXTENSÃO; MOSTRA DE INICIAÇÃO CIENTÍFICA DA UNICRUZ, 4. 2001, Cruz Alta, RS. Anais... Cruz Alta: UNICRUZ, 2001.

MELO, E.G. et al. Aloenxerto ósseo cortical: avaliação do seu emprego em tíbia de cão. Arquivo Brasileiro de Medicina Veterinária e Zootecnia, v.50, n.4, p.385-394, 1998.

PELKER, R.R. et al. Effects of freezing and freeze-drying on the biomechanical properties of rat bone. Journal of Orthopaedic Research, v.1, n.4, p.405-411, 1984.

SALBEGO, F.Z. et al. Teste de resistência biomecânica de implantes ósseos corticais conservados em glicerina a $98 \%$ e submetidos a diferentes tempos de reidratação. In: CONGRESSO
DO COLÉGIO BRASILEIRO DE CIRURGIA E ANESTESIOLOGIA VETERINÁRIA, 7., 2006, Santos, SP. Anais... Belo Horizonte: Arq Bras Med Vet Zoot, v.58, supl., p.77-78, 2006.

SOUZA, S.A. Ensaios mecânicos de materiais metálicos. São Paulo: Edgar Blücher, 1974. 235p.

STEVENSON, A. Enxertos ósseos. In: SLATER, D. Manual de cirurgia de pequenos animais. 2.ed. São Paulo: Manole, 1998. v.2, cap.127, p.2006-2017.

ZILIOTTO, L. et al. Utilização de implante ósseo cortical alógeno conservado em glicerina para preservação de membro torácico: estudo experimental em cães. Acta Cirúrgica Brasileira, v.18, n.2, p.107-115, 2003. 